\title{
15 Years of Intelligent Container Research
}

\author{
Reiner Jedermann (1) and Walter Lang (1)
}

\begin{abstract}
Food losses in the cool chain, which are mostly caused by temperature deviations, can be reduced by remote monitoring of transport conditions. The project 'Intelligent Container' was begun 15 years ago to provide the necessary sensor system, communication and automated evaluation of data. If transport and delivery planning are adjusted according to the actual quality or the predicted remaining shelf life, more products arrive with sufficient quality at the customers. This paper summarizes the project results and highlights current trends in industrial application and research, such as commercial remote container monitoring and standards for data exchange, sub-GHz communication, the increasing availability of biological and computational fluid dynamics models and digital twins. Open research topics include the development of specialized sensors. To overcome obstacles hindering the industrial application of sensor quality monitoring, we suggest a gradual approach, with lower company resources required for the first action points. Food losses can be reduced, even if the complete system, including permanent remote access and adaptive stock rotation, is not applied.
\end{abstract}

\section{Introduction}

Fifteen years ago, we set our research focus on the 'Intelligent Container' as a means to mitigate food losses caused by temperature abuse and deviating environmental conditions during logistic operations. The Intelligent Container provides remote monitoring to detect transport problems as early as possible and predict resulting effects on food quality, using the length of the remaining shelf life as a scale. The container operates as an autonomous system by predicting the shelf life condition

R. Jedermann $\cdot$ W. Lang $(\bowtie)$

Institute for Microsensors, -Actuators and -Systems (IMSAS), University of Bremen, Bremen Germany

e-mail: rjedermann@imsas.uni-bremen.de; wlang@imsas.uni-bremen.de 
in which the product will arrive at the destination point. If it is foreseeable that the product will not arrive with sufficient quality, a warning message will be generated.

The loss of food quality is a gradual process, often hidden to visual inspection until it is too late (Nunes et al. 2014), i.e. manual quality inspections at the end of a transport process will often not reveal the effects of previous harmful temperature conditions. Later in the distribution centre, at the retailer or even at the private customer, the product will decay long before its printed use-by date.

The means to reveal such invisible losses is to calculate the shelf life based on the product's temperature and sensory history. This approach can be well integrated into warehouse management. According to the first-expires-first-out (FEFO) principle, products with a low shelf life are assigned to nearby destinations, and products with high shelf lives are held back for longer transport routes. By using this intelligent stock rotation, the effects of deviating transport conditions, often not visible from the outside, can be mostly compensated, and more products arrive at the customer with a quality level above the acceptance threshold. A survey in (Jedermann et al. 2014a) showed that this approach could reduce losses of highly perishable products by $8 \%$ to $14 \%$ of the total transported volume.

\subsection{Outline}

In this paper, we will provide a short overview of the project history and present the most important findings. International research and industrial applications have further advanced since the completion of our field tests on ocean vessels in 2013. We summarize these current developments and analyze obstacles that still hinder the broad application of the FEFO concept. Finally, we list three subsequent action points by which companies can begin to reduce losses and mitigate temperature problems, even if only a small budget and resources are available.

\subsection{Project History}

There are several reasons to fix the birth of the Intelligent Container to the year 2006, although the term was used previously and the Collaborative Research Centre SFB637 on autonomous logistic processes began two years earlier. A first study with three industrial partners on the magnitude of temperature deviations began in 2006, founded by an internal budget of the Bremen Research Cluster for Dynamics in Logistics (LogDynamics). In the same year, a small-scale demonstrator was presented at the Hannover trade fair (Fig. 1). The webpage http://www. intelligentcontainer.com/ was registered, and the first journal paper was published (Jedermann et al. 2006).

The transfer of research results to the industry was started in 2008 by a sub-project of the SFB637 with three companies: Cargobull, a provider of truck 


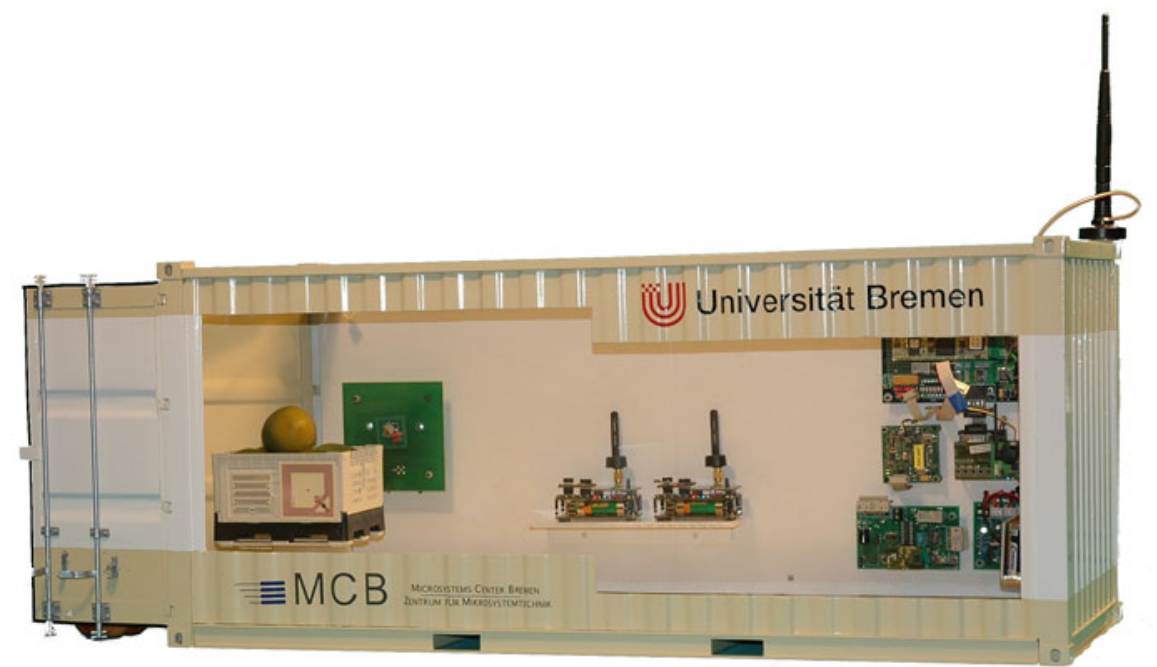

Fig. 1 Model container (1:8) for demonstration purposes (Jedermann et al. 2007a). The initial concept included the following steps: New freight items are scanned by RFID (left). Sensor nodes supervise the environmental conditions (middle). The processing module (right) calculates shelf life prediction

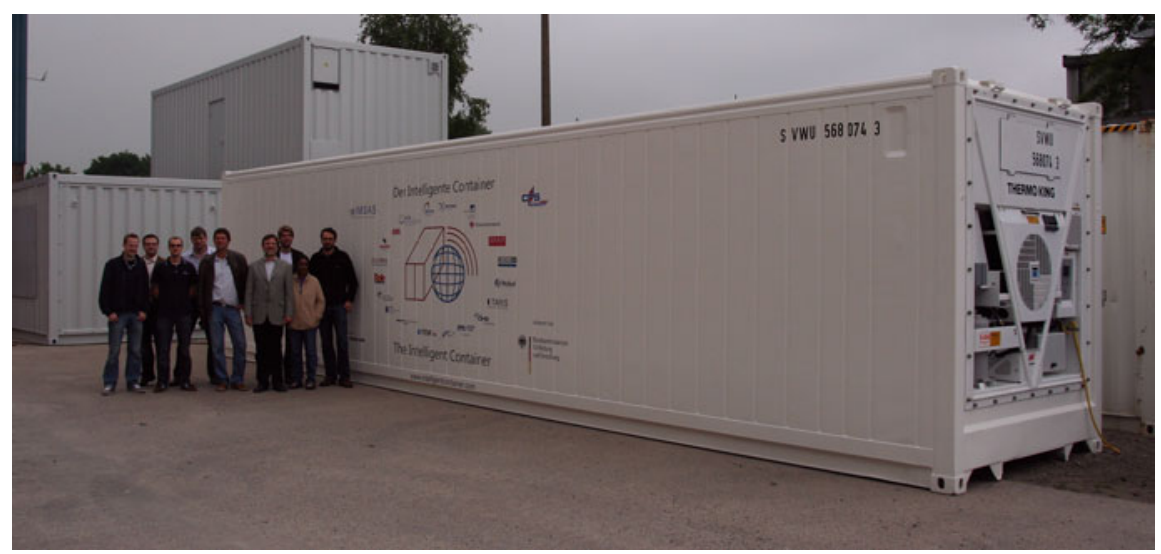

Fig. 2 Full-size prototype of the intelligent container and research team of Bremen University Bremen

telematics, Rungis Express, a delicacy food trading company, and Dole Fresh Fruit as an importer for bananas. Tests for the wireless sensor monitoring of bananas in ocean containers commenced in 2009 (Fig. 2). In 2010, the cooperation broadened to an Innovation Alliance with 15 industrial and 6 research partners, leading to the publication of a dedicated theme issue on 'Intelligent Food Logistics' in 2014 (Jedermann et al. 2014a). Subsequent projects covered the analyses of airflow 


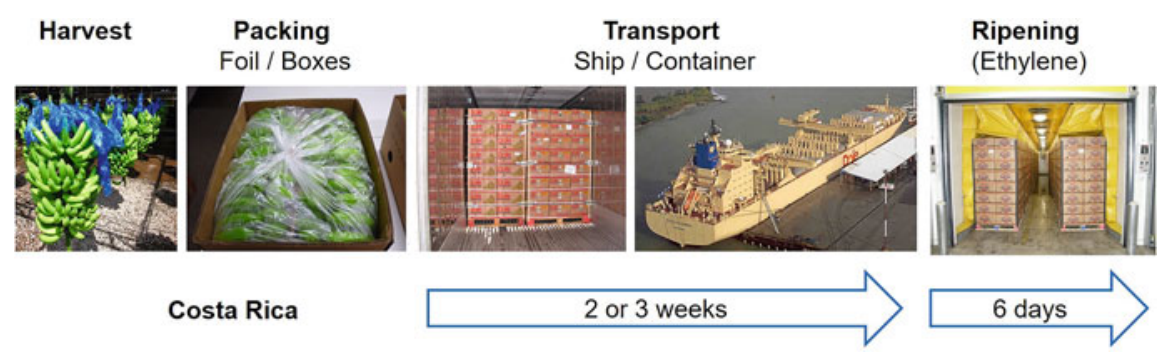

Fig. 3 Main elements of the cooling chain for bananas (see text for details)

conditions in cold storage warehouses by wireless anemometers (Hartgenbusch et al. 2020), the detection of ethylene by micro-fabricated gas sensors (Sklorz et al. 2012a,b) and the detection of fungi spores (Papireddy Vinayaka et al. 2016).

\subsection{The Banana Chain}

Most of our experimental work was dedicated to bananas. We carried out five test transports with a sensor and communication-equipped container. Bananas were harvested green in Central America, packed into boxes, stacked to pallets, stowed to reefer containers, trucked to the harbour and shipped to Europe (Fig. 3). Bananas were stowed 'warm' to the container. Cooling began when the container was connected to a power supply at the harbour in Central America. In Europe, the pallets were stored in a climatized warehouse for a few days or weeks and trucked to a ripening facility in Germany. There, the conversion from starch to sugar with the outside colour change from green to yellow was initiated by exposure to ethylene gas. Commercial ripening is only feasible with completely green bananas; otherwise, it is not possible to achieve uniform good quality. Bananas must arrive at the ripening facility before their green life ends. We monitored the process from stowing the pallets to the container until the completion of the ripening process.

\section{Findings}

Our project results cover various fields, from sensor development, electronics and communication to biological research and logistic models. 


\subsection{Omnipresence of Temperature Deviations}

Although we have only anecdotical evidence, we tend to say that, 'Wherever you measure temperature, you find deviations'. During our very first temperature data logger test in a refrigerated delivery truck, we observed a strange spike. Later, we learned that the cooling unit had run out of oil, but the driver was able to fix it after an hour.

Particularly in smaller companies, awareness of maintaining correct temperatures without interruption is lacking. A supplier of meat agreed on participating in a temperature monitoring study. Thus, he proved himself guilty of not cooling during transport from slaughterhouse to depot. He was banned from the suppliers' list by the import company with the consequence that we had to adapt microbiological models to another meat product in our project.

The average temperature over two weeks' transportation of bananas in ocean containers was between $2.5^{\circ} \mathrm{C}$ and $4.9{ }^{\circ} \mathrm{C}$ above the setpoint during our tests (Jedermann et al. 2019). The deviations of the average container temperature are overlaid with temperature heterogeneity in vertical and horizontal directions (Fig. 4). The vertical temperature mostly follows a regular pattern with an increase of approximately $1{ }^{\circ} \mathrm{C}$ from the lowest to the sixth box layer on the pallet. Further, upward to the eighth top layer, temperature slightly decreases due to additional cooling by the horizontal flow of return air.

Deformations of containers and pallets of several centimetres from an ideal cuboid shape cause an irregular distribution of gap diameters and airflow. Thus, the horizontal temperature pattern is rather erratic. For new, up-to-date equipment, we observed a horizontal variation $1.5^{\circ} \mathrm{C}$, with higher values for older containers.

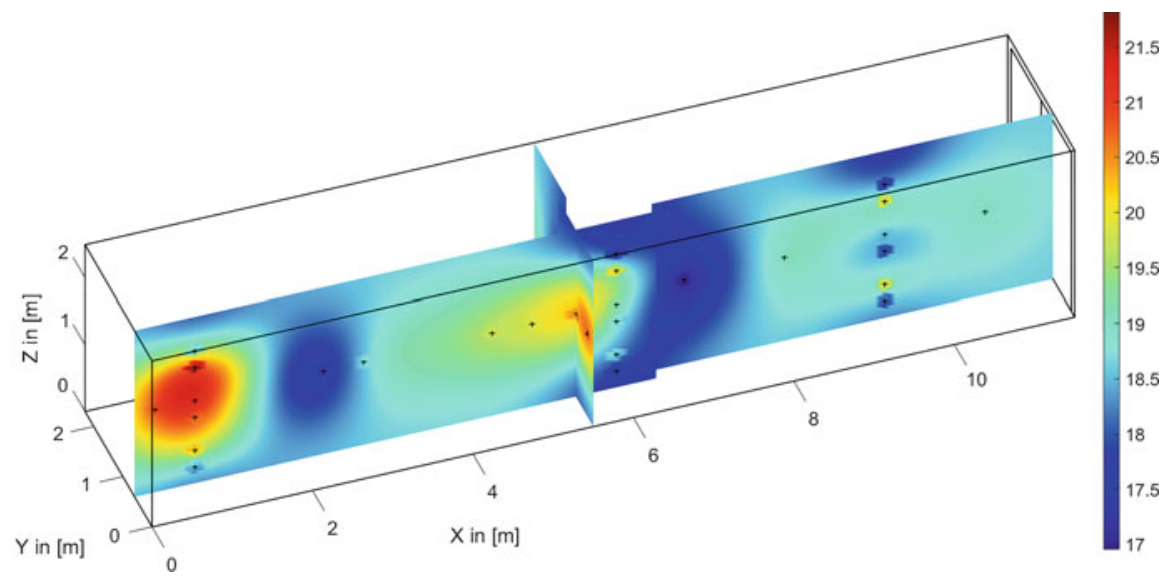

Fig. 4 Average temperature during an ocean transport of bananas in March 2011 with a temperature setpoint of $14.4^{\circ} \mathrm{C}$. Crosses mark the sensor positions. Temperature on the slice planes was interpolated by Kriging 
A 12-year-old container required more than double the time to cool to a stable temperature, and after two weeks' cooling, it was still $1.5^{\circ} \mathrm{C}$ above the setpoint (Jedermann et al. 2014c).

Temperature fluctuations over the length of the container can be analyzed using a variogram (Jedermann et al. 2011). Measurement points with a distance larger than the variogram range only contribute to the common average but have no further statistical relation. To capture the spatial temperature profile, the sensor distances must be less than the variogram range. For banana containers, we estimated a variogram range between 1.13 and 1.65 meters (Jedermann et al. 2011).

Other authors found temperature variations of similar magnitude, e.g., Pelletier et al. (2011) observed a temperature increase of $4.5{ }^{\circ} \mathrm{C}$ after 5 days of truck transportation. According to a survey by Ndraha et al. (2018), temperature limits were overstepped in $13.6 \%$ to $58 \%$ of transports.

During a truck transport of grapes in Brazil, a 4 to $11{ }^{\circ} \mathrm{C}$ temperature variation was observed (Oliveira et al. 2021). Humidity varied from $60 \%$ to $98 \%$. The shelf life differed by a factor of almost two depending on the calculated mass loss.

Human and machinery failure can cause much higher temperature abuse than the above-described variations on regular transports. The most important reasons for claims are, according to (Castelein et al. 2020), reefer unit malfunction and power failures, followed by failing to cool products before stowing (hot stuffing), incorrect temperature setpoint, poor packing and poor cargo quality at loading. Delays at transhipment, leaving pallets without cooling at the platform, is another serious cause of temperature variation (Nunes et al. 2014), particularly due to an insufficient workforce at peak seasons.

\subsection{Necessity of Sub-GHz Communication and Gateway}

Translating a laboratory system into a real-world test is always cumbersome. One of our most challenging experiences was that $2.4 \mathrm{GHz}$ wireless sensors do not work if placed between bananas. A later theoretical model, tuned by our experimental data on signal strength, showed that $2.4 \mathrm{GHz}$ radio waves are attenuated by $-62 \mathrm{~dB}$ per meter by packed bananas (Jedermann et al. 2014b). Communication was only possible over a maximum distance of $50 \mathrm{~cm}$. This problem can be solved by switching to sub- $\mathrm{GHz}$ radio modules. For $866 \mathrm{MHz}$, the attenuation drops to $-8.3 \mathrm{~dB} / \mathrm{m}$ and for $433 \mathrm{MHz}$ to $-2.2 \mathrm{~dB} / \mathrm{m}$. Sub-GHz sensors with Lora, Dash7 and proprietary protocols were successfully tested to penetrate a stack of apple crates over 2 to 5 meters (Jedermann et al. 2018).

Not only water-containing food products but also the metal hull of containers hinder radio communication. Penetration of a metal box requires high radio power, which is not feasible for battery-powered devices. The recommended solution consists of a gateway that connects the low-power internal wireless network with external communication. This gateway can also be connected to the power supply of the cooling unit and has, therefore, a higher energy budget for communication. 
The freight supervision unit in our Intelligent Container links the internal wireless sensor network with external Wi-Fi, GSM and Iridium satellite communication. It also provides a platform to calculate shelf life models and generate warning messages. The functionality of the system could be verified in several field tests.

\subsection{Shelf- and Green-Life Models}

Understanding the complete kinetics of the chemical and enzymatic reactions causing quality and shelf life loss is not practical. Laboratory data are typically limited to external attributes such as colour, firmness and weight loss. The dependency of these attributes to the sample's temperature history can be modelled by using a simplified approach:

The product has an initial budget of shelf life after harvest. A certain amount is subtracted every day, depending on the temperature. At optimal conditions, one day of shelf life is lost per day of transportation. The loss per day (LPD) is accelerated by deviating transport conditions. The simplest form of the LPD is given by an exponential function of temperature, or it can be more accurately calculated by the Arrhenius Law for reaction kinetics (Jedermann et al. 2014c). By switching from a day-wise calculation to an integral form, arbitrary temperature curves can be used as input for the shelf life model as in our model for the green life of bananas (Jedermann et al. 2014c).

The model assumes that a temperature deviation at the beginning of the cool chain has the same effect as a deviation of the same height and length at the end of the chain or two separate deviating events with both half lengths. In the latter case, more temperatures fluctuations can lead to condensation and, thus, increased bacterial growth.

More elaborate models attempt to predict the change of quality attributes by using temperature-dependent differential equations for the concentration and activity of enzymes, e.g., models developed by the Frisbee project for apples and packed cooked ham (Gwanpua et al. 2015). The model for apples also includes the influence of air humidity on moisture loss. The identification of 10 or even more model parameters sets high demands on the extent of laboratory experiments.

As a compromise, bacterial growth can be described by common pattern functions, such as the Gompertz function applied in our project for meat products (Bruckner et al. 2013).

\subsection{Ethylene Detection}

Ripening fruits can communicate. For example placing a ripe banana between green bananas initiates the ripening of the other bananas. The trigger is ethylene, a gaseous ripening hormone. The effect works in both directions: climacteric fruits 
react to ethylene, and ethylene is produced by the fruit after the ripening has begun. High-resolution measurement of ethylene will be useful for the management of fruit logistics because it can directly detect the ripening status of the fruits in the container.

In gas chromatography, the adsorption and desorption of a gas in a chromatographic column are used to separate gases. To achieve resolution in the ppm range, the ethylene gas is accumulated in a pre-concentrator before chromatographic measurement (Janssen et al. 2014). In the last 20 years, small and autonomously working micro-gas chromatographic systems for ethylene have been developed. The fluidic system is miniaturized down to a size of approximately $10 \mathrm{~cm}$. The critical parts, i.e. the chromatographic column and the pre-concentrator, are made using silicon micro-technology (Sklorz et al. 2012a). Ethylene can be detected in the 10-ppb range (Zaidi et al. 2017). Since 2015, it has been possible to replace expensive silicon with robust and low-cost materials, such as 3D polymer printing for the columns (Lucklum et al. 2015) and ceramics for pre-concentrators (Zaidi et al. 2018).

An alternative method to sense ethylene is to measure the specific infrared light absorption of ethylene molecules at $10.6-\mu \mathrm{m}$ wavelength by NDIR (non-dispersive infrared spectroscopy) (Sklorz et al. 2012b). The method is highly robust and easier to implement than gas chromatography, but the resolution is only in the 10-ppm (part per million) range. Extending the resolution to the ppb range using advanced systems and pre-concentrators is possible but has yet to be developed for container applications (Popa and Udrea 2019; da Silveira Petruci et al. 2014).

\subsection{Models for Heat Removal and Generation}

The cooling unit of a container must remove heat from three different sources: compensation for isolation losses of the container walls, remaining field heat from the product in case of insufficient or missing pre-cooling and heat generated by the product itself. The later heat load can become the highest factor for climacteric fruits, such as bananas. Biological processes and respiration continue after harvest. The conversion from starch to sugar produces large amounts of the heat up to $200 \mathrm{~W} /$ ton during ripening, whereas green unripe bananas produce only $20 \mathrm{~W} / \mathrm{ton}$ to $50 \mathrm{~W} /$ ton depending on temperature and atmosphere conditions (Jedermann et al. 2014c). If the produced heat extends the local heat removal by cooling of typically $30 \mathrm{~W} /$ ton to $100 \mathrm{w} /$ ton, a hotspot is generated with uncontrollable temperature rises.

The local heat removal per box is subject to variations in packing and diameters of air gaps between the pallets. Our model for bananas (Jedermann and Lang 2014) enables to describe heat removal and generation by two separate proportional factors. If the bananas begin to ripen, the latter factor can increase after a few days or weeks. The first factor can be identified by the temperature data from the first week of container transport. Thereafter, the actual heat generation can be estimated, and the formation of a hotspot can be detected in an early state. 
This monitoring system enables the artificial ripening of bananas to be carried out directly in the transport container. The cargo hold is exposed to ethylene, and the temperature is slightly increased to initiate ripening. Thereafter, the temperature is gradually decreased to maintain the ripening process at a moderate speed and heat generation without overstepping the cooling capacity.

\subsection{Case Study on Cool Chain Logistics}

The possible reduction of food losses by the Intelligent Container was evaluated in a case study on bananas (Haass et al. 2015). Temperature-related losses were simulated for a logistic network between a harbour in Central America and ten customers in Europe. After arrival in one of three European ports, containers were to be reassigned to another customer depending on their predicted remaining green life. Simulation parameters were tuned according to an analysis of the existing logistic network and order quantities provided by one of our project partners. The assumption of probabilistic distribution of banana quality from an earlier study (Lütjen et al. 2013) was replaced by a green life model providing a more accurate prediction of losses.

The scenario with conventional containers, without information about green life changes, resulted in $4.27 \%$ losses of the total transported volume. Reassignment of deliveries according to the actual green life prediction reduced the losses by $0.37 \%$. Accepting short delays in delivery enables more flexible transport reassignments. If additionally, causes of temperature deviations are detected earlier by the Intelligent Container, losses can be reduced by $0.88 \%$ at a maximum.

\subsection{Detection of Fungus Spores}

Mould is substantial danger in the transport of food (Pitt and Hocking 2009). To detect fungus, spores are caught on a nutrient medium surface, where they can grow. The growing mould changes the medium's $\mathrm{pH}$, and this can be detected by impedance measurement (Papireddy Vinayaka et al. 2016). Alternatively, the pH change can be used to trigger a colour change detected by a camera.

Classically, the growth of fungal colonies on a culture medium is observed using a light microscope by a trained human observer. This observation has successfully been performed by computer vision and image recognition (Tahir et al. 2018). Fungal spores are immobilized, grown, an optic micrograph is taken, and the fungus colonies are identified and counted by a convolutional neural network (Blank et al. 2016). 


\subsection{Difficulties in Quality Measurement and Prediction for Green Bananas}

Bananas have the highest seaborne reefer cargo volume per year for any fruit (Castelein et al. 2020). The fact that all partners in the cool chain were in the hand of one company simplified our tests from the farm to the ripening facility in Germany. Nevertheless, the achievable savings by FEFO are generally quite limited for bananas. The simulation showed that $0.88 \%$ of total volume losses could be avoided by adaptive order assignment. This value is substantially less than the previously mentioned savings for other highly perishable food products (8-14\%).

Green bananas are a highly robust product if handled with care and stored at the correct temperature. Under a controlled atmosphere, they can last for 2 months or longer in a warehouse. The artificial ripening process evens out all differences in green banana ages. Only turners with visible colour changes must be excluded from ripening.

However, there are other points contributing to the 'nastiness' of bananas: a green banana is just a green banana. There is no outside indicator to determine the age of a green banana-neither colour, firmness, nor respiration activity. A laboratory examination of enzyme concentrations is far beyond feasible in transport supervision. The only way to predict green life is based on temperature history, supported by additional data on the atmosphere, harvest age and growing conditions.

Green life models can provide recommendations regarding which pallets should be prioritized for further processing, but they are far from predicting the precise day on which the banana will turn from green to yellow. The green life model has a typical standard deviation of \pm 5 days (Jedermann et al. 2014c). This biological variance adds to the effect of temperature variation inside one container, being the larger one of the two (Fig. 5).

Although FEFO brings only limited advantages for bananas, our project results demonstrated that the banana chain profits largely from remote quality monitoring. Maladjusted temperature set points, power and machinery failures are detected immediately. In case of general quality problems, the farm can be informed before the next ship is sent on its way, transporting containers with most likely the same quality problem. Replacement deliveries can be organized in time; this ability is particularly crucial if boxes with a quality problem were branded for a specific customer. The temperature setpoint of the cooling unit can be fine-tuned according to the actual box temperature. The effect of alternate packing and stowage schemes was verified by our tests. Finally, we could demonstrate that container ripening is feasible based on detailed sensor control and modelling. 


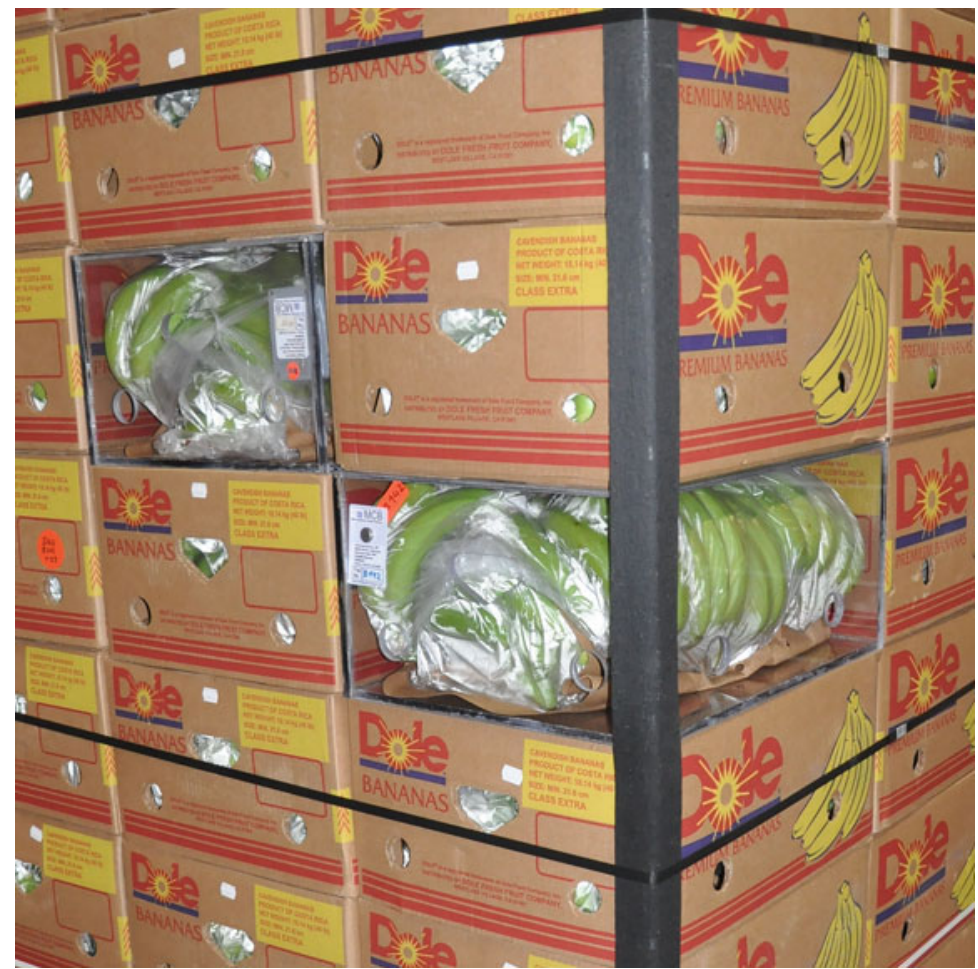

Fig. 5 Monitoring temperature changes as cause for green life variations. Wireless temperature/humidity sensor (middle box) and temperature data logger (corner box). Transparent boxes were only used for demonstration purposes

\section{Current Developments and Trends}

'Food cold chain management' is a growing research area according to a review by Shashi et al. (Shashi et al. 2020) of 1189 journal papers. The number of published papers doubled within 4 years to 216 papers in 2019. The authors identified four major research clusters. The first cluster a) is centred around RFID technologies and shelf life management. The other three clusters cover non-technical topics, such as b) production, harvesting and transport planning, c) causes and management of postharvest waste and d) methods and quality standards for the identification of problematic areas.

The limitation of cluster a) to RFID is that it appears not to represent the full bandwidth of current research and industrial applications. In the following section, we introduce communication technologies, standards, models and processing platforms that go beyond our initial concept for the Intelligent Container. 


\subsection{Communication}

Communication is the most advancing aspect of remote cool chain control. Maersk began to equip their reefer containers with remote container monitoring (RCM) based on GSM communication in 2016 (Zarkani and Rasmussen 2016). More than 400 ocean vessels were equipped with a satellite dome to forward GSM data packets from the containers. In 2019, the system was extended by the 'Captain Peter' App (Avery 2019), giving all their customers instant and easy access to data of container location, temperature setpoint and cooling engine status. Nevertheless, the system is focused on monitoring those parameters that are the responsibility of the transport operator, i.e. the correct setup and operation of the cooling unit and timely delivery, but not its content status. An interface to wireless sensors inside the cargo was announced but hardly applied in practice.

LoRaWAN (long-range wide-area network) allows communication with low data rates in license-free sub-GHz frequency bands. We demonstrated that LoRa radio signals could penetrate 4.5 meters of fruits with only moderate packet losses of $1.5 \%$ (Jedermann et al. 2018), making it a highly suitable candidate for communication with packed food products inside a container. However, LoRaWAN has been, so far, mostly applied to the outside communication of containers, e.g., on the vessel or in harbour settings, where cellular networks are not available (Avery 2020).

Besides the communication range, the network capacity is a crucial factor, such as in a harbour setting with thousands of containers. According to (Gambiroža et al. 2019), the capacity of the LoRaWAN network is still an open research issue, depending on the assignment of data rates, number of end devices and external disturbances in the frequency range. They summarize the results of 10 capacity studies. A network with 8000 devices can, for example transmit 500 packets/min, which is far more than sufficient to transmit the hourly status data of containers.

Narrowband Internet-of-Things (NB-IOT) enables cellular communication with an extremely low energy budget. Loggers have a battery life of 8 years (Ako Electromecànica 2020). But they face the same problem as other GSM loggers [e.g., (MOST Tech Sweden AB 2021)] in that the metal hull of the container and signal attenuation by water-containing products hinder communication with the next cell tower at some kilometres' distance.

A more detailed survey of available RCM and wireless data logger hardware can be found in our earlier publication (Jedermann et al. 2017).

\subsection{Standards}

In the Intelligent Container, we adapted standards such as XML data structures, IPv6 and the Constrained Application Protocol (CoAP) (Jedermann et al. 2014b), mixed with proprietary protocols, particularly in the lower protocol layers. In recent years, 
wireless sensor networks have moved towards widely accepted standards, such as the LoRaWAN protocol. RFID Sensors can use available data fields in the EPC Gen-2 protocol to transmit temperature data.

The need for trans-company interoperability has been recognized by ocean carriers. The Digital Container Shipping Association (DCSA) was founded in 2019 with the goal to define open and freely accessible standards for the global container shipping industry. Up to now, their member list includes 9 of the top 10 ocean carriers. Their track and trace (T\&T) standards were published on SwaggerHub and GitHub (DCSA 2021).

\subsection{Modelling}

The biological modelling of the quality behaviour of food products is still an active research area. The FRISBEE project published six detailed shelf life models (Bruckner et al. 2013). The University of Tasmania, Australia, has offered a website to access over 100 computational biological models to predict the growth of various food pathogens by the partly commercial CB-Premium service (https:// www.cbpremium.org/) since 2018 (Tamplin 2018).

The growing number of freely available models simplifies the adaptation of FEFO concepts. However, even if a model for a particular product is already available, the model must be fine-tuned to local varieties, weather and growing conditions in order to provide an accurate prediction of shelf life variations as a function of the sensory production and transport histories. Biological experiments are still necessary, although in a reduced number.

Another area of growing research interest is the computational fluid dynamics (CFD) modelling of packing, for example to optimize their layout and the location and size of vent holes (Ambaw et al. 2017). The complete simulation of a loaded container is still beyond current computational capacities. Modelling is only feasible with some simplifications, such as replacing product pallets and air gaps with porous media (Moureh et al. 2009) or modelling only empty containers (Getahun et al. 2018). Such CFD models are useful for optimizing packing and stowage layouts and detecting general airflow and ventilation problems causing insufficient cooling. However, the actual temperature distribution largely depends on factors that are hardly measurable or predictable, such as varying gap diameters (Jedermann and Lang 2017), as well as container and pallet deformations.

\subsection{Modelling Platforms, Cloud Computing and Digital Twins}

When we began in 2008 with the initial tests on remote truck monitoring, our partner company was proud to have negotiated a GSM flat rate for $400 \mathrm{kByte}$ per month. The limited communication volume drove the need for intelligent data processing 
directly inside the means of transportation. The automated detection of critical events was one of the key concepts of the Intelligent Container with the idea to reduce external communication, mostly to warning messages on such events.

Today, the inclusive volume of data tariffs has increased by a factor of 1000 or even more. Edge processing - as implemented in the Intelligent Container-is still useful for robustness in case of communication failures but no longer absolutely necessary. The trend has moved toward cloud computing and data analysis on the server level.

Our first concepts were based on mobile and autonomous software agents (Jedermann et al. 2007b), which made decisions on behalf of the freight owner, e.g., assessment of quality risks and, in case of detected problems, searching for an alternate destination with a shorter transport route.

Decision support tools (DSC) (Mack et al. 2013) are another term to describe the data processing by an Intelligent Container. The DSC analyzes temperature and additional sensor data by shelf life models and generates warnings and recommendations regarding how to adjust transport planning.

Today, the focus has broadened from isolated shelf life and temperature distribution models to more holistic approaches. Digital twins pursue to provide a detailed and accurate representation of real-world objects, such as a pallet of food products or other transport entities. Digital twins combine physical properties, such as size and weight, information from an electronic waybill and sensory data with extensive modelling tools. Digital twin platforms provide standard interfaces to collect data from multiple sources and interlink different types of models, such as CFD, shelf life, weather and traffic models.

Digital twins have been applied in structural health monitoring and smart manufacturing (Lu et al. 2020) and recently also in the supply chain (Defraeye et al. 2021). A special challenge is the modelling of uncertainty. Whereas mechanical systems have mostly well-known and accurate models, biological models have a high level of unknown input factors, side-effects and biological variance. These uncertainties must be represented, processed and evaluated in the digital twin platform.

Machine learning has become a hot topic in recent years, driving the idea of replacing cumbersome laboratory experiments on shelf life models with autonomous learning based on data from remote transport monitoring. Enthusiastic concepts often underestimate the size of the necessary training database and related costs. The training data must contain sufficient instances of all combinations of input factors, e.g., temperature, humidity, mechanical damages and scars during packing. Otherwise, the machine learning overfits to single deviating events. The dogma of garbage in garbage out is also true for machine learning (Camacho et al. 2018). Furthermore, supervised learning requires target output values, i.e. an evaluation of the actual product quality as a result of its transport history. The generation of such data requires manual laboratory analysis of the samples. A simple yes/no value if there had been a subsequent customer complaint provides only coarse information. 


\section{Conclusions and Action Points}

The availability of technical components for the Intelligent Container has largely increased in recent years. New reefer trucks and containers are mostly sold with built-in remote monitoring facilities. The numbers of available wireless sensors systems, data loggers and published shelf life models are also growing.

Pilot studies have shown that losses of perishable products can be reduced by $8 \%$ to $14 \%$ of the total transport volume by scheduling deliveries according to the FEFO principle (Jedermann et al. 2014a). Nevertheless, FEFO has yet to find its way into practice to any significant degree.

\subsection{Obstacles for FEFO Implementation}

The obstacles that hinder FEFO's implementation must be questioned. One point is that FEFO does not fit every product and every chain. Less sensitive products with long shelf lives profit less from FEFO. Rescheduling of deliveries is mostly feasible for high-volume products with several alternate customers. If there are no products with a higher shelf life available in the warehouse, the retailer would be more likely to risk providing low-quality products than having empty shelves.

More severely, missing links on both technical and operational sides obstruct the commercial application of the FEFO concept:

Missing Link between Internal and External Communication The large-scale application of RCM by Maersk and the growing number of companies offering wireless data loggers show that there is a business case both for external and internal monitoring of containers with perishable products. However, interfaces that link these two system layers are still missing.

The manufacturers of wireless data loggers provide their own cloud platforms instead of integrating into existing RCM systems. Offering 'data as a service' is a more lucrative business model than merely selling the hardware.

Missing Cost Sharing Models for Sensor Monitoring Cool chains are mainly divided into different operators (Jedermann et al. 2017) with different interests, quality management targets for their services, profits from increased shelf life and responsibilities and costs for contributing to remote quality monitoring. The one who pays for sensors and communication tends not to be the one who ultimately profits, e.g., the producers must place sensors in the product packing but have no direct benefit. Logistic service providers for reefer trucks and containers must install the communication system to prove that their equipment is running at the correct temperature without interruption. However, this can also backfire in case of problems and raise customer complaints. The distribution centres profit from FEFO by reducing customer complaints and in-warehouse losses, mostly without physical contact to the sensor hardware. The retailers must collect the sensors. They receive 
products with a more predictable average shelf life and profit from higher customer satisfaction.

The fragmented chain makes it impossible to create a business case for the individual operators, who must be linked not only on the logistical side but also in the goal to minimize losses at the end of the chain and share related costs.

\subsection{Recommended Practical Actions}

Food losses by temperature abuse are often significant and cannot be accepted in a world of limited environmental resources, although the obstacles and investments are often too high to implement FEFO in a specific cool chain. Therefore, we suggest a set of three subsequent actions (Jedermann et al. 2019). Even if only the first action can be implemented due to limited budget and resources, losses can be reduced substantially.

Action 1: Offline Data Logger Study The first and most important action identifies and mitigates cool chain ruptures. Offline, low-cost, reusable temperature loggers are packed to the products in repeated tests to analyze the chain's performance. No dedicated communication infrastructure has to be installed at this stage. Such a study often reveals avoidable gaps in the cool chain, e.g., power interruptions during harbour handling, extended periods on loading platforms without cooling, wrong temperature setpoints and high-temperature variation inside the cargo hold due to insufficient air circulation by careless stowing.

Weak spots in the chain can be identified and corrected, e.g., excluding older reefer containers, which had more than twofold temperature deviations compared with up-to-date equipment in our tests (Gwanpua et al. 2015). The effect of correct pre-cooling at the farm or production site on the temperature performance of the subsequent transport is also often under-estimated. The rule-of-thumb that ' 1 hour delay in pre-cooling costs 1 day of shelf life' is mostly true, according to (Pelletier et al. 2011).

Action 2: Detection of Actual Problems by Live Data Action 2 switches from occasional offline data collection to regular real-time or live access, at least at some control points, such as arrival at the harbour or distribution centre. Permanent live monitoring requires more investments for mobile communication but also provides increased benefits. Power failures and defective cooling equipment, which are one major cause of cool chain raptures, can be detected immediately. In general, the earlier information arrives, the more time there is to plan and correct subsequent steps, e.g., prioritizing container handling in the harbour according to their degree of temperature deviation, ordering a replacement delivery in case of a large excess of temperature limits and informing the producer about possible problems.

Action 3: Intelligent Stock Rotation by FEFO If the product's temperature history is available, even as the logistical process continues, losses can be further 
reduced by adaptive delivery planning and stock rotation according to the FEFO concept. Products with low remaining shelf life are assigned to the shortest transport routes. Necessary investments include the analysis of the product-specific relation between temperature and shelf life. Existing models can serve as a starting point after some fine-tuning. Based on collected data from regular transport monitoring and detailed examination product quality for some samples, the model can be later refined.

\subsection{Research on New Sensor Types}

'Temperature' is the environmental condition with the highest impact on fruit quality. The accuracy of shelf life prediction and the early detection of transport problems will be improved if other sensor types are added, e.g., atmosphere conditions such as humidity, $\mathrm{O}_{2}$ and $\mathrm{CO}_{2}$ concentration. Sensors for other important contributing factors to transport quality and safety are still an open research topic:

Development of New NDIR Sensors Experience has shown that micro-gas chromatographic systems are difficult to implement for autonomous operations. Hence, it seems advisable to improve non-dispersive infrared measurement (NDIR) for ethylene detection. Today, NDIR resolves the lower ppm range, whereas for containers, a ppb resolution would be necessary. Recently, new NDIR systems using hollow waveguide technology have been demonstrated (da Silveira Petruci et al. 2014). They require much less gas, which would allow combining an NDIR sensor with a micromachined pre-concentrator. This way, theoretically, a resolution of $50 \mathrm{ppb}$ is possible. Furthermore, using two different infrared wavelengths, a combined system, which could also measure ethylene and fumigation gases such as methyl bromide or phosphine, will be possible.

Identification of Pest Insects in the Container Cargo pest insects are a major risk in overseas transport. Countries invest significant efforts into control and law enforcement to prevent invading species. Once an insect species has invaded, it is almost impossible to suppress it. A sad example is the progress of the Chinese rose beetle, which invaded Hawaii. An extensive biological control program had no success in stopping its spread (Stanaway et al. 2001). It is recommended to develop a system that can not only detect the presence of insects in a container but also identify them and provide a warning if dangerous species are found. One possibility might be using adhesive traps and pattern recognition.

Summary Various research efforts have been carried out to reduce food losses in the last two decades. The detection of temperature abuse and the FEFO concept are two of the main contributions. The technical basis has already been provided by the Intelligent Container and supported by recent developments in commercial RCM and sensor hardware. Further research is still necessary to foster action three by additional pilot studies, which are the development of dedicated shelf life models, 
more detailed quantification of possible loss reductions by the FEFO concept, and research in new sensor types.

Acknowledgements The initial research was supported by the German Research Foundation (DFG) as part of the Collaborative Research Centre 637 'Autonomous Cooperating Logistic Processes', followed by the industrial cooperation project 'The Intelligent Container' supported by the Federal Ministry of Education and Research, Germany, under reference number 01IA10001. The project COOL for monitoring cold storage warehouses and the project Camsense for particle measurement in the air were supported by the Federal Ministry for Economic Affairs and Energy based on a decision by the German Bundestag.

The Joint Project MaUS-An Autonomous Microreactor System for Detection of Mould Contaminations-was founded by the German Federal Ministry of Education and Research. The development of an in-situ ethylene measurement system was founded by AiF-IGF.

We wish to thank our research partners, particularly Ulrike Praeger and Martin Geyer from the Leibniz Institute for Agricultural Engineering and Bioeconomy (ATB), Potsdam and Judith Kreyenschmidt from the Institute for Animal Sciences (ITW), Bonn. Among the several industrial partners, we particularly thank Dole for their cooperation for more than 7 years in various projects. We also thank Mike Nicometo, a former member of the Cool Chain Association, for his advice on the project and for co-editing a theme issue on intelligent food logistics.

\section{References}

Ako Electromecànica. Case Study: Multinational Transport (Refrigerated Div.). https:// www.ako.com/products/wireless-temperature-moisture-monitoring/nb-iot-temperaturehumidity-logger/ (2020)

Ambaw, A., Mukama, M., Opara, U.L.: Analysis of the effects of package design on the rate and uniformity of cooling of stacked pomegranates: numerical and experimental studies. Comput. Electron. Agric. 136, 13-24 (2017). https://doi.org/10.1016/j.compag.2017.02.015

Avery, P.: Maersk takes next step with reefer monitoring. In: WorldCargo News, England, https:// www.worldcargonews.com/news/news/maersk-takes-next-step-with-reefer-monitoring-61619 (2019)

Avery, P.: ORBCOMM rolls out LoRa on vessels. In: WorldCargo News, England, https:// www.worldcargonews.com/news/orbcomm-rolls-out-lora-on-vessels-6532 (2020)

Blank, R., Vinayaka, P.P., Tahir, M.W., Yong, J., Vellekoop, M.J., Lang, W.: Comparison of several optical methods for an automated fungal spore sensor system concept. IEEE Sensors J. 16(14), 5596-5602 (2016). https://doi.org/10.1109/JSEN.2016.2567538

Bruckner, S., Albrecht, A., Petersen, B., Kreyenschmidt, J.: A predictive shelf life model as a tool for the improvement of quality management in pork and poultry chains. Food Control. 29(2), 451-460 (2013). https://doi.org/10.1016/j.foodcont.2012.05.048

Camacho, D.M., Collins, K.M., Powers, R.K., Costello, J.C., Collins, J.J.: Next-generation machine learning for biological networks. Cell. 173(7), 1581-1592 (2018). https://doi.org/ 10.1016/j.cell.2018.05.015

Castelein, B., Geerlings, H., Van Duin, R.: The reefer container market and academic research: a review study. J. Clean. Prod. 256, 120654 (2020). https://doi.org/10.1016/ j.jclepro.2020.120654

da Silveira Petruci, J.F., Fortes, P.R., Kokoric, V., Wilk, A., Raimundo, I.M., Cardoso, A.A., Mizaikoff, B.: Monitoring of hydrogen sulfide via substrate-integrated hollow waveguide mid-infrared sensors in real-time. Analyst. 139(1), 198-203 (2014). https://doi.org/10.1039/ c3an01793a 
Digital Container Shipping Association (DCSA): Track \& Trace Standards. https://dcsa.org/ standards/track-trace/, last accessed 2021/05/28

Defraeye, T., Shrivastava, C., Berry, T., Verboven, P., Onwude, D., Schudel, S., Rossi, R.M.: Digital twins are coming: will we need them in supply chains of fresh horticultural produce? Trends Food Sci. Technol. 109, 245-258 (2021). https://doi.org/10.1016/j.tifs.2021.01.025

Gambiroža, J. Č., Mastelić, T., Šolić, P., Čagalj, M.: Capacity in LoRaWAN Networks: challenges and opportunities. In: 2019 4th International Conference on Smart and Sustainable Technologies (SpliTech), 1-6 (2019) https://doi.org/10.23919/SpliTech.2019.8783184

Getahun, S., Ambaw, A., Delele, M., Meyer, C.J., Opara, U.L.: Experimental and numerical investigation of airflow inside refrigerated shipping containers. Food Bioprocess Technol. 11(6), 1164-1176 (2018). https://doi.org/10.1007/s11947-018-2086-5

Gwanpua, S.G., Verboven, P., Leducq, D., Brown, T., Verlinden, B.E., Bekele, E., et al.: The FRISBEE tool, a software for optimising the trade-off between food quality, energy use, and global warming impact of cold chains. J. Food Eng. 148, 2-12 (2015). https://doi.org/10.1016/ j.jfoodeng.2014.06.021

Haass, R., Dittmer, P., Veigt, M., Lütjen, M.: Reducing food losses and carbon emission by using autonomous control - a simulation study of the intelligent container. Int. J. Prod. Econ. 164, 400-408 (2015). https://doi.org/10.1016/j.ijpe.2014.12.013

Hartgenbusch, N., Borysov, M., Jedermann, R., Lang, W.: Characterization and design evaluation of membrane-based calorimetric MEMS sensors for two-dimensional flow measurement. IEEE Sensors J. 20(9), 4602-4609 (2020). https://doi.org/10.1109/JSEN.2020.2965332

Janssen, S., Tessmann, T., Lang, W.: High sensitive and selective ethylene measurement by using a large-capacitiy-on-chip preconcentrator device. Sensors Actuators B Chem. 197, 405-413 (2014). https://doi.org/10.1016/j.snb.2014.02.001

Jedermann, R., Lang, W.: Model based estimation of biological heat generation during cold-chain transport and processing. In: 3rd IIR International Conference on Sustainability and the Cold Chain, St Mary's University, Twickenham, London, UK (2014)

Jedermann, R., Lang, W.: Computational fluid dynamics modelling of deviating airflow and cooling conditions in banana containers. In: V International Symposium on Applications of Modelling as an Innovative Technology in the Horticultural Supply Chain - Model-IT 2015, Wageningen, Netherlands, 193-200 (2017) https://doi.org/10.17660/ActaHortic.2017.1154.25

Jedermann, R., Behrens, C., Westphal, D., Lang, W.: Applying autonomous sensor systems in logistics-combining sensor networks, RFIDs and software agents. Sensors Actuators A Phys. 132(1), 370-375 (2006). https://doi.org/10.1016/j.sna.2006.02.008

Jedermann, R., Behrens, C., Laur, R., Lang, W.: Intelligent containers and sensor networks, approaches to apply autonomous cooperation on systems with limited resources. In: Hülsmann, M., Windt, K. (eds.) Understanding Autonomous Cooperation and Control in Logistics - the Impact on Management, Information and Communication and Material Flow, pp. 365-392. Springer, Berlin (2007a). https://doi.org/10.1007/978-3-540-47450-0_25

Jedermann, R., Gehrke, J.D., Becker, M., Behrens, C., Morales-Kluge, E., Herzog, O., Lang, W.: Transport scenario for the intelligent container. In: Hülsmann, M., Windt, K. (eds.) Understanding Autonomous Cooperation and Control in Logistics - the Impact on Management, Information and Communication and Material Flow, pp. 393-404. Springer, Berlin (2007b). https://doi.org/10.1007/978-3-540-47450-0_24

Jedermann, R., Palafox-Albarrán, J., Barreiro, P., Ruiz-García, L., Robla, J.I., Lang, W.: Interpolation of spatial temperature profiles by sensor networks. Sensors., 2011 IEEE, 778-781 (2011). https://doi.org/10.1109/ICSENS.2011.6127148

Jedermann, R., Nicometo, M., Uysal, I., Lang, W.: Reducing food losses by intelligent food logistics. Phil. Trans. R. Soc. A. 372(2017), 20130302 (2014a). https://doi.org/10.1098/ rsta.2013.0302

Jedermann, R., Lloyd, C., Poetsch, T.: Communication techniques and challenges for wireless food quality monitoring. Phil. Trans. R. Soc. A. 372(2017), 20130304 (2014b). https://doi.org/ 10.1098/rsta.2013.0304 
Jedermann, R., Praeger, U., Geyer, M., Lang, W.: Remote quality monitoring in the banana chain. Phil. Trans. R. Soc. A. 372(2017), 20130303 (2014c). https://doi.org/10.1098/rsta.2013.303

Jedermann, R., Praeger, U., Lang, W.: Challenges and opportunities in remote monitoring of perishable products. Food Packag. Shelf Life. 14(A), 18-25 (2017). https://doi.org/10.1016/ j.fps1.2017.08.006

Jedermann, R., Borysov, M., Hartgenbusch, N., Jaeger, S., Sellwig, M., Lang, W.: Testing Lora for food applications - example application for airflow measurements inside cooled warehouses with apples. Procedia Manuf. 24, 284-289 (2018). https://doi.org/10.1016/ j.promfg.2018.06.026

Jedermann, R., Praeger, U., Geyer, M., Lang, W.: Temperature deviations during transport as a cause for food losses. In: Yahia, E. (ed.) Preventing Food Losses and Waste to Achieve Food Security and Sustainability. Burleigh Dodds, Sawston (2019)

Lu, Y., Liu, C., Wang, K.I.K., Huang, H., Xu, X.: Digital twin-driven smart manufacturing: connotation, reference model, applications and research issues. Robot. Comput. Integr. Manuf. 61, 101837 (2020). https://doi.org/10.1016/j.rcim.2019.101837

Lucklum, F., Janssen, S., Lang, W., Vellekoop, M.J.: Miniature 3D gas chromatography columns with integrated fluidic connectors using high-resolution stereolithography fabrication. Procedia Eng. 120, 703-706 (2015). https://doi.org/10.1016/j.proeng.2015.08.761

Lütjen, M., Dittmer, P., Veigt, M.: Quality driven distribution of intelligent containers in cold chain logistics networks. Prod. Eng. 7(2-3), 291-297 (2013). https://doi.org/10.1007/s11740-0120433-3

Mack, M., Garbade, M., Hebel, M., Kreyenschmidt, J.: Development of a decision support tool for different meat supply chains. In: 5th International Workshop Cold Chain Management, Bonn, Germany (2013)

MOST Tech Sweden AB: Take full control of your supply chain. https://most.tech/ last accessed 2021/05/28

Moureh, J., Tapsoba, M., Flick, D.: Airflow in a slot-ventilated enclosure partially filled with porous boxes: Part II - measurements and simulations within porous boxes. Comput. Fluids. 38(2), 206-220 (2009). https://doi.org/10.1016/j.compfluid.2008.02.007

Ndraha, N., Hsiao, H.-I., Vlajic, J., Yang, M.-F., Lin, H.-T.V.: Time-temperature abuse in the food cold chain: review of issues, challenges, and recommendations. Food Control. 89, 12 21 (2018). https://doi.org/10.1016/j.foodcont.2018.01.027

Nunes, M.C.N., Nicometo, M., Emond, J.P., Melis, R.B., Uysal, I.: Quality improvement in fresh fruit and vegetable logistics: berry logistics field studies. Phil. Trans. R. Soc. A. 372(2017), 20130307 (2014). https://doi.org/10.1098/rsta.2013.0307

Oliveira, C.C.M.D., Oliveira, D.R.B.D., Silveira Junior, V.: Variability in the shelf life of table grapes from same batch when exposed under different ambient air conditions. Food Sci Technol. 41, 290-300 (2021). https://doi.org/10.1590/fst.14220

Papireddy Vinayaka, P., Van den Driesche, S., Blank, R., Tahir, M.W., Frodl, M., Lang, W., Vellekoop, M.J.: An impedance-based Mold sensor with on-chip optical reference. Sensors. 16(10), 1603 (2016). https://doi.org/10.3390/s16101603

Pelletier, W., Brecht, J.K., do Nascimento Nunes, M.C., Emond, J.-P.: Quality of strawberries shipped by truck from California to Florida as influenced by postharvest temperature management practices. HortTechnology. 21(4), 482-493 (2011)

Pitt, J.I., Hocking, A.D.: Fungi and Food Spoilage, vol. 519. Springer, Boston, MA (2009)

Popa, D., Udrea, F.: Towards integrated mid-infrared gas sensors. Sensors. 19(9) (2019). https:// doi.org/10.3390/s19092076

Shashi, Centobelli, P., Cerchione, R., Ertz, M.: Food cold chain management: what we know and what we deserve. Int. J. Supply Chain Manag. 26(1), 102-135 (2020). https://doi.org/10.1108/ SCM-12-2019-0452

Sklorz, A., Janssen, S., Lang, W.: Application of a miniaturised packed gas chromatography column and a $\mathrm{SnO} 2$ gas detector for analysis of low molecular weight hydrocarbons with focus on ethylene detection. Sensors Actuators B Chem. 180, 43-49 (2012a). https://doi.org/10.1016/ j.snb.2011.12.110 
Sklorz, A., Janßen, S., Lang, W.: Detection limit improvement for NDIR ethylene gas detectors using passive approaches. Sensors Actuators B Chem. 175, 246-254 (2012b). https://doi.org/ 10.1016/j.snb.2012.09.085

Stanaway, M.A., Zalucki, M.P., Gillespie, P.S., Rodriguez, C.M., Maynard, G.V.: Pest risk assessment of insects in sea cargo containers. Aust. J. Entomol. 40(2), 180-192 (2001). https:/ /doi.org/10.1046/j.1440-6055.2001.00215.x

Tahir, M.W., Zaidi, N.A., Rao, A.A., Blank, R., Vellekoop, M.J., Lang, W.: A fungus spores dataset and a convolutional neural network based approach for fungus detection. IEEE Trans. Nanobioscience. 17(3), 281-290 (2018). https://doi.org/10.1109/TNB.2018.2839585

Tamplin, M.L.: Integrating predictive models and sensors to manage food stability in supply chains. Food Microbiol. 75, 90-94 (2018). https://doi.org/10.1016/j.fm.2017.12.001

Zaidi, N.A., Tahir, M.W., Vellekoop, M., Lang, W.: Using Allan variance to determine the resolution of ethylene gas chromatographic system. Sensors., 2017 IEEE, 1-3 (2017). https:// doi.org/10.1109/ICSENS.2017.8233919

Zaidi, N.A., Tahir, M.W., Vellekoop, M.J., Lang, W.: Design of Novel Ceramic Preconcentrator and Integration in gas chromatographic system for detection of ethylene gas from ripening bananas. Sensors. 18(8), 2589 (2018). https://doi.org/10.3390/s18082589

Zarkani, S., Rasmussen, C. H.: Remote reefer monitoring looking back and looking forward. In: Cool Logistics Global, 8th global conference, Bremen, Germany (2016)

Open Access This chapter is licensed under the terms of the Creative Commons Attribution 4.0 International License (http://creativecommons.org/licenses/by/4.0/), which permits use, sharing, adaptation, distribution and reproduction in any medium or format, as long as you give appropriate credit to the original author(s) and the source, provide a link to the Creative Commons license and indicate if changes were made.

The images or other third party material in this chapter are included in the chapter's Creative Commons license, unless indicated otherwise in a credit line to the material. If material is not included in the chapter's Creative Commons license and your intended use is not permitted by statutory regulation or exceeds the permitted use, you will need to obtain permission directly from the copyright holder. 